\title{
Impact of the Covid-19 Pandemic on Early Childhood Care and Education
}

c) Springer Nature B.V. 2020

The Covid-19 pandemic has resulted in monumental changes to education throughout the world. According to UNESCO (2020), nearly $90 \%$ of the world's student population-over 1.5 billion learners in 165 countries-have had their learning experiences disrupted by precautions and policies implemented to quell the spread of the disease. Jaime Saavedra, Global Director for Education, describes it as the "largest simultaneous shock to all education systems in our lifetimes" (World Bank 2020). More specific to early childhood education, this international health crisis has precipitated unprecedented, sweeping, and dramatic changes in the lives of children and their families, preservice and inservice teachers of young children, and early childhood teacher educators. Worldwide, the Covid-19 has also pushed the early childhood education system to the verge of collapse and mobilized leading early childhood organizations to advocate for Covid-19 financial packages to protect early education programs (NAEYC 2020; Zero to Three 2020).

Medical research suggests that, strictly speaking, Covid19 is not a "children's disease" because, up to this point, there are few confirmed cases of the coronavirus in the young and, even among children who contract the disease, the fatality rate has been very low (Spaull 2020). Yet when we consider all aspects of young children's development, the profound implications of this global pandemic are evident. Covid-19 not only suspended normal childhood activities such as attending school, interacting with extended family and friends, playing outdoors, and exploring nature but also disrupted the consequent socio-emotional benefits that accrue from children's engagement in these experiences.

Children are inherently vulnerable because they depend on adults to have their most basic needs met. When those adults lack the wherewithal to cope with the immediate, urgent, and multiple adaptive demands a pandemic places on families and when support systems do not exist, falter, or cease, it can result in unmitigated disaster for the very young. As Xafis (2020) notes, the most affected "are those individuals routinely disadvantaged by the social injustice created by the misdistribution of power, money and resources" (unpaged). Particularly for children who are living in poverty, chronically ill, have disabilities, experience housing and food insecurity, reside in remote areas, are marginalized by mainstream society (e.g., indigenous people and migrant workers), or are suffering from neglect or abuse, problems are exacerbated by pandemics. As concerning as these immediate and observable consequences of Covid-19 for young children are, even less is known about what the long-term effects may be.

From a scholar's perspective, we are now "participants in the biggest unplanned experiment that education has ever seen in our lifetimes" (Thomas and Rogers 2020, unpaged). Whether or not Covid-19 stays true to its categorization as a novel virus, nearly every article or book chapter on the topic has a 2020 publication. Research is so recent that much of the material is published online and not yet available in hard copy. Furthermore, the situation remains fluid, with some of the early assertions being revised or revoked as new evidence accumulates. Although the information explosion associated with Covid-19 was first concentrated in the medical and health fields, it now spans disciplinary boundaries.

It is a source of professional pride that our publisher for Early Childhood Education Journal, Springer Nature, took swift and decisive action to disseminate information by making all their publications on Covid-19 available, free of charge. After reviewing these materials, as well as those published by leading professional organizations and other respected publishers, early childhood education was not well represented in the literature. When we proposed two distinct projects:

(1) a special issue of Early Childhood Education Journal and.

(2) an edited book on Covid-19 for the series, Educating the Young Child, 
Springer Nature gave their immediate and enthusiastic support to the concept.

Through a series of email conversations and a review of the Calls for Papers of other editors, we formulated a strategy. The first challenge was that the typical way of identifying contributors-by looking at their previous publications on the subject matter-was virtually inaccessible, given the recency of the topic. It is difficult to determine who in our field is currently engaged in inquiry related to the pandemic or to predict who might be sufficiently interested to become well steeped in the international and interdisciplinary literature. There is a definite need for curated information about Covid-19 and early childhood education and high-quality published resources are an important form of support in our field. This combined Call for Papers, both for a special issue of Early Childhood Education Journal and a call for contributors of chapters for an edited book in the series Educating the Young Child is one step toward identifying authors to write authoritatively about some aspect of the phenomenon.

Timeline for Articles:

Special Issue of Early Childhood Education Journal $(\boldsymbol{E} \boldsymbol{C E J})$

Timeliness is an important consideration in this project. To facilitate that goal, we are asking prospective authors of articles for ECEJ to submit an abstract of not more than 300 words by September 1st. The editors will provide feedback on the concept for the article early in the process rather than waiting until an entire manuscript has been prepared. Following the example of other editors, we will expedite the peer review process and have proposed a tight timeline, as follows.

Abstracts due: September 1st.

Notification of acceptance: September 20th.

Manuscripts due: January 4th.

Reviews to authors: February 30th.

Revisions completed and final manuscripts due: May 15th.

Publication of special issue: September, 2021.

Notification of acceptance.

\section{Timeline for Book Chapters}

\section{Educating the Young Child (EDYC)}

The Educating the Young Child book series has published 17 volumes since its inception in 2008. To learn more about the series, visit https://www.springer.com/series/7205?detai lsPage $=$ titles.

Chapter abstract (500 words) due: October 15 th.

Notification of acceptance: October 30th.

Chapter drafts due: April 15th.

Comments from the editor returned to chapter authors: June 15th.

Chapter revisions due: August 15th.
Book submitted to Springer Nature for review by the Editorial Board of the Educating the Young Child series and/or external review: October 30th, 2021.

\section{Abstract Submission}

Please submit your abstract (for the journal issue and the edited book) to this email: ecejcovid19@gmail.com.

NOTE: Please add the following to the "subject" line based on where you want to submit your manuscript:

Subject line:

ABSTRACT FOR COVID-JOURNAL ISSUE ABSTRACT FOR COVID-BOOK CHAPTER

After you submit the abstract, you will receive an email with the editors' decision on your abstract, manuscript guidelines, and manuscript submission guidelines.

\section{Editors}

Jyotsna Pattnaik from California State University, Long Beach and Mary Renck Jalongo, editor-in-chief of ECEJ from 1995-2019, will be guest co-editors of the special issue of Early Childhood Education Journal in consultation with the current editor-in-chief, Patricia Crawford from University of Pittsburgh. Jyotsna Pattnaik will serve as the editor for the edited book in the Educating the Young Child Series published by Springer Nature. The editors will give authors a quick turnaround time on abstracts and expedite the review process.

\section{Types of Manuscripts}

For the purposes of the journal and for the book chapters, we define the early childhood years as infancy- 8 years of age. Any manuscript submitted should focus on that age group and professionals who specialize in working with the very young. The readership of the journal and of the book series is a diverse, international group; therefore, collaborative efforts of scholars from different parts of the world are welcomed. The editors are receptive to reviews of research if they include implications for early childhood practice. Original research-quantitative, qualitative, and mixed methods-is welcomed. All research must conform to ethical standards and principles of informed consent. University faculty members need to verify that the research has been approved by their Institutional Review Boards for compliance with the ethical treatment of human subjects. Manuscripts that offer critical analysis of existing policies and provide recommendations for future policies on the health pandemic are highly encouraged. Authors may contribute 
both an article to the journal and a chapter to the book if their abstracts are approved; however, the two works need to be different and distinct from one another.

\section{General Manuscript Format for the Special Issue of ECEJ}

Articles should not exceed 30 pages of 12-point print, Times New Roman typeface with everything double-spaced. This page count includes references, tables, figures, graphs, and child drawings or writings that authors choose to include. Please use the American Psychological Association Style, $6^{\text {th }}$ edition.

\section{General Manuscript Format for the Edited Book in the Educating the Young Child Series}

Book chapters should not exceed 27 pages with one-inch margins, and everything double-spaced in Times New Roman typeface 12-point print. This page estimate includes references, tables, figures, graphs, and child drawings or writings that authors choose to include. Strive for not more than 7,000-8,500 words (including references). Please use the American Psychological Association Style $6^{\text {th }}$ edition to guide to format the headings, in-text citations, reference list, figures, tables, and captions.

\section{Suggested Topics}

This list is by no means exhaustive but may serve as a starting point for formulating ideas. Topics below are suitable not only for the articles submitted to the special issue of Early Childhood Education Journal but also for the edited book in the Series, Educating the Young Child.

- History of health pandemics and their consequences for young children. Interagency collaborations to support children and families during health crises.

- Ongoing effects of the Covid-19 pandemic on Early Childhood Education and Care throughout the world

- Clinical and epidemiological characteristics of Covid-19 in young children and implications for health care practices and systems

- Impact of Covd-19 on preschool and primary teachers' perspectives and practices

- Supporting young children, birth through eight years of age, with special needs during the Covid-19 pandemic, such as foster children, chronically ill children, and children with mental health issues, who need regular access to professionals in related fields
- Social and emotional health of all young children due to physical distancing during the Covid-19 pandemic

- Preschool program administrators' perspectives on the impact of Covid-19 on the well-being of children, staff, and their programs (publicly funded programs, private programs, parochial programs, family child-care programs)

- Impact of Covid-19 on children and families living in vulnerable urban contexts such as refugee camps and informal settlements

- Covid-19 related professional development issues and opportunities for early childhood education and care professionals during the pandemic

- Perspectives of parents and families of young children on the impact of Covid-19 on their children's education, health, and well-being

- Supporting families of color with young children who have been disproportionately impacted by the Covid-19 pandemic

- Identification of high-quality educational resources and effective strategies to support families engaged in home schooling to comply with physical distancing practices

- A critical analysis of child-care policies (e.g., Federal CARES Act; Economic Injury Disaster Loan (EIDL), licensing regulations) and programs (such as the Paycheck Protection Program) that relate to the Covid-19 health crisis

- Perspectives of social workers, therapists, and professionals in various fields who are working with young children and families during the pandemic

- Efforts by postsecondary institutions to maintain professional standards despite disruptions to early childhood courses and professional practicum experiences

- Ways for university faculty members specializing in early childhood care and education have managed to sustain scholarship when research plans are disrupted, conferences are cancelled, and publishers are working remotely

Given the diverse readership of Early Childhood Education Journal and the book series, Educating the Young Child as well as the interdisciplinary implications of a global pandemic, we are particularly eager to see collaborative efforts that look beyond the local context and involve networking with other early childhood experts, including professionals in related fields.

These uncertain times test our collective ability to quickly adapt, cope with multiple personal and professional challenges, and support those most burdened by the shockwaves of Covid-19. Perhaps now, more than ever before, young children and families, teacher candidates, and graduate students are relying on experts in the field of early childhood to support, advocate, and lead. Springer Nature's special issue of Early Childhood Education Journal and the edited 
book for the Educating the Young Child Series are a way to provide authoritative information, professional insights, and research-based recommendations to professionals in early childhood care and education.

\section{References}

National Association for the Education of Young Children. (2020). NAEYC COVID 19 statement. Available: https://www.naeyc.org/ resources/blog/naeyc-covid-19-statement.

Spaull, N. (2020). COVID-19 and schooling in South Africa: Who should go back to school first? Prospects. Available: https://link. springer.com/content/pdf/10.1007\%2Fs11125-020-09470-5.pdf.

Thomas, M. S. C., \& Rogers, C. (2020). Education, the science of learning, and the COVID-19 crisis. Prospects. Available: https:// link.springer.com/article/10.1007/s11125-020-09468-z.

United Nations Educational, Scientific and Cultural Organization (UNESCO). (2020). COVID-19 educational disruption and response. Paris: Author. Available: https://en.unesco.org/news/ covid-19-educational-disruption-and-response.

World Bank. (2020). The COVID-19 pandemic: Shocks to education and policy responses. Available: https://www.worldbank.org/en/ topic/education/publication/the-covid19-pandemic-shocks-toeducation-and-policy-responses.

Xafis, V. (2020). 'What is inconvenient for you is life-saving for me': How health inequities are playing out during the COVID-19 pandemic. Asian Bioethics Review. Available: https://link.springer. com/content/pdf/10.1007\%2Fs41649-020-00119-1.pdf.

Zero to Three. (2020). How COVID-19 is impacting child-care providers. Available: https://www.zerotothree.org/resources/3398-howcovid-19-is-impacting-child-care-providers.

Publisher's Note Springer Nature remains neutral with regard to jurisdictional claims in published maps and institutional affiliations. 